\title{
Umbilical cord blood lead levels
}

Lead is toxic to the developing brain. Even low blood lead concentrations affect intelligence $[1,2]$. It is an independent, significant and inversely related risk factor for mental development in the first two years [3, 4].

A study on human umbilical cord blood lead levels has documented lower levels in centres with lead-free petrol [5]. Sri Lanka discontinued the use of leaded petrol in 2002. We report on umbilical cord blood lead levels in Colombo one year after the change over to lead-free petrol.

This cross sectional descriptive study was done in May and June 2003 with ethical approval from the Faculty of Medicine, Colombo. We randomly selected pregnant women from four maternity homes in the Colombo Municipality serving as homogenous lower middle class urban community, and the De Soysa Hospital for Women, Colombo. Informed consent was obtained and $2 \mathrm{~mL}$ each of maternal venous blood and umbilical cord blood were collected into lead-free containers. Risk factors for lead exposure such as occupation of pregnant woman and spouse, and other environmental risk factors were gathered using an interviewer administered questionnaire. Birth weight and gestational age were noted.

Blood samples were analysed for lead at the Occupational Hygiene and Safety Division of the Labour Department in Colombo by atomic absorption spectrometry.

Twenty four mothers and their infants were investigated. They were from urban and semi-urban maternal residences and of similar lower middle class socioeconomic background. The maternal age ranged from 19 to 33 years (mean 27 years). Mean birth weight was $2678 \mathrm{~g}$ (Table 1). The mean blood lead level in mothers was $3.31 \pm 1.49 \mu \mathrm{g} / \mathrm{dL}$. Only one mother had no blood lead and her baby had no lead either. Of the 24 newborns 17 had assayable quantities of lead in their blood stream. The overall mean umbilical cord blood level was $0.43 \pm$ $0.46 \mu \mathrm{g} / \mathrm{dL}$.

The highest amount of lead in cord blood was $75 \%$ of the maternal value. The correlation between maternal and cord blood levels was not strong $(r=0.36)$. Since our study sample was small, environmental and occupational risk factors for lead exposure were not statistically analysed.

Lead acts as a developmental neurotoxin by interfering with neuronal migration, cell proliferation and synapse formation in the developing nervous system. We found $71 \%(17 / 24)$ of babies born in Colombo to have assayable quantities of lead in their blood stream at birth. The values we got were low, but prospective studies have shown that adverse effects occur even with lead levels previously considered safe [1].
Table 1. Maternal and umbilical cord blood lead levels

\begin{tabular}{ccccc}
\hline Ref. & Maternal & Birth & \multicolumn{3}{c}{ Blood lead levels $(\mu g /$ dL) $n=48$} \\
No. & age (years) & weight $(g)$ & Umbilical cord & Maternal \\
\hline 1 & 30 & 2950 & 0 & 0 \\
2 & 33 & 2670 & 0 & 1 \\
3 & 28 & 2510 & 0 & 1.4 \\
4 & 21 & 2650 & 0 & 1.6 \\
5 & 32 & 2560 & 0 & 3 \\
6 & 30 & 3800 & 0 & 3.4 \\
7 & 19 & 2800 & 0 & 4.5 \\
8 & 26 & 2850 & 0.1 & 2 \\
9 & 25 & 2340 & 0.1 & 2.5 \\
10 & 23 & 2560 & 0.1 & 3.5 \\
11 & 24 & 2770 & 0.1 & 3.7 \\
12 & 32 & 2400 & 0.2 & 5 \\
13 & 30 & 2640 & 0.4 & 2.5 \\
14 & 30 & 3350 & 0.4 & 4.5 \\
15 & 28 & 2850 & 0.4 & 5 \\
16 & 33 & 3250 & 0.4 & 5.5 \\
17 & 29 & 2930 & 0.6 & 3 \\
18 & 21 & 780 & 0.8 & 4.2 \\
19 & 31 & 2290 & 1 & 3.5 \\
20 & 25 & 2704 & 1 & 3.5 \\
21 & 22 & 3010 & 1 & 4.5 \\
22 & 24 & 2160 & 1 & 6 \\
23 & 30 & 2900 & 1.2 & 3.7 \\
24 & 28 & 2550 & 1.5 & 2 \\
\hline
\end{tabular}

Eliminating tetraethyl lead from petrol lowers cord blood lead levels [5]. The major source of fetal lead is believed to be maternal bone. Even in the absence of lead in the external environment, the long resident time of lead in trabecular ( 3 years) and cortical bone ( 30 years) exposes the fetus to contamination [6], and demineralisation during pregnancy mobilises the lead from maternal bone stores [3]. Our study confirms that despite the reduction of lead in the environment by discontinuing leaded petrol [7], the problem of fetal lead exposure has not been eradicated.

It has been reported that umbilical cord lead levels are about $70 \%$ of the maternal value [8]. Lead crosses the placental barrier by active transport. We did not find a strong correlation between maternal and fetal blood lead levels and hence do not recommend estimating the level of fetal lead by measuring maternal blood levels. Given the harm that even a miniscule of lead can cause to mental development we recommend biomonitoring programmes to safeguard women and children from this neurotoxic metal.

\section{Acknowledgements}

We thank Ms Ramya Malkanthi, Senior Scientist, Occupational and Safety Division, Department of Labour, Colombo for analysing the blood samples, and Director, 


\section{Research letters}

De Soysa Maternity Hospital for Women, Colombo and Chief Medical Officer, Colombo Municipal Council for permission to carry out this study.

\section{References}

1. Schwartz J. Low level lead exposure and children's IQ : a meta analysis and search for a threshold. Environmental Research 1994; 65: 42-55.

2. Senanayake MP, Sumanasena SP. Cognitive development of lead-exposed children near Borella junction. Sri Lanka Journal of Child Health 2003; 32: 15-17.

3. Gomaa A, Hu H, Bellinger D, Schwartz J, Tsaih S-W, et al. Maternal bone lead as an independent risk factor for fetal neurotoxicity: a prospective study. Pediatrics 2002; 110: $110-8$.

4. Gardella C. Lead exposure in pregnancy: a review of the literature and argument for routine prenatal screening. Obstetrics and Gynecological Survey 2001; 56: 231-8.
5. Smargiassi A, Takser L, Masse A, Sergerie M, Mergler $\mathrm{D}$, et al. Comparative study of manganese and lead levels in human umbilical cord and maternal blood from two urban centers exposed to different gasoline additives. Science of Total Environment 2002; 290: 157-64.

6. Chuang HY, Schwartz J, Gonzales-Cossio T, Lugo MC, Palazuelos E, et al. Interrelations of lead levels in bones, venous blood and umbilical cord blood with exogenous lead exposure through maternal plasma lead in peripartum women. Environmental Health Perspectives 2001; 109: 527-32.

7. Changing atmospheric lead levels in Colombo with discontinuation of leaded petrol in Sri Lanka. A report by Environmental Division of National Building Research Organization, Colombo, Sri Lanka, February 2003.

8. Furman A, Laleli M. Maternal and umbilical cord blood lead levels : an Istanbul study. Archives of Environmental Health 2001; 56: 26-8.

Manouri P Senanayake, Professor and Head, M D Asiri Rodrigo, Demonstrator and J Kudalugoda Arachchi, Lecturer, Department of Paediatrics, Faculty of Medicine, Kynsey Road, Colombo 8, Sri Lanka

Correspondence: M P Senanayake, Tel: +94 11 2695300, e-mail: <manouri_senanayake@yahoo.co.uk> (Competing interests : none declared). Received 10 November 2003 and revised version accepted 20 February 2004. 